\title{
The vulnerability of native rangeland plant species to global climate change in the West Asia and North African regions
}

\author{
Azaiez Ouled Belgacem • Mounir Louhaichi
}

Received: 29 April 2012 / Accepted: 17 January 2013 / Published online: 31 January 2013

(C) The Author(s) 2013. This article is published with open access at Springerlink.com

\begin{abstract}
This study aimed to evaluate the impact of climate change on the geographical distribution of selected native species from two areas from West Asia and North Africa. Three species representing two genera were selected for assessment of their vulnerability to climate change. The first species was Salsola vermiculata L. which is common to both study areas. The second genus was represented by two species, Haloxylon salicornicum (Moq.) Bunge from the Syrian rangelands and H. schmittianum Pomel from southern Tunisia. To assess the vulnerability of these species to climate change we used ecological-based models. The data inputs were composed of the species occurrence data and the environmental data which included eight climatic layers, three soil property layers in addition to an altitude layer. Since environmental parameters only enable assessing the sensitivity of target species to climate change, a grazing pressure layer was used to assess the species vulnerability. Only climatic parameters were considered as changing across three periods; current situation, 2020 and 2050. The main results indicated that threatened range species, such as $S$. vermiculata which were subjected to continuous grazing pressure, showed high vulnerability to climate change as expressed by the predicted decrease in the areas of their distribution. However, species with low palatability and broad ecological niches (i.e. H. salicornicum and H. schmittianum) had an advantage due to the reduced competition for water and nutrients. An adaptation strategy to increase the resilience of the most vulnerable species should involve management of grazing pressure and the establishment of other mitigation measures.
\end{abstract}

\footnotetext{
A. Ouled Belgacem

International Center for Agricultural Research in the Dry Areas (ICARDA),

Arabian Peninsula Regional Program, Dubai, UAE

e-mail: a.belgacem@cgiar.org

M. Louhaichi $(\triangle)$

International Center for Agricultural Research in the Dry Areas (ICARDA), Amman, Jordan e-mail:m.louhaichi@cgiar.org
} 


\section{Introduction}

Climate change is increasingly recognized as one of the greatest challenges to humankind and all other life on Earth (Fitzpatrick et al. 2008). The scenarios developed by the Intergovernmental Panel on Climate Change (IPCC) project a further increase in global mean surface temperature of $2-6^{\circ} \mathrm{C}$ above pre-industrial levels by 2100 , increased incidence of floods and droughts, and spatial and temporal changes in precipitation patterns (IPCC 2007). All studies have warned that the negative impacts of climate change will become much more intense and frequent, particularly if combined with continuous environmentally destructive human activities (Nordblom and Shomo 1993). The potential ecological impact of ongoing climate change has been highly debated in recent years. It is forecasted that, by the end of the century, climate change and its impacts may be the dominant direct driver of biodiversity loss and changes in ecosystem services at the global level (Phillips et al. 2006).

Although the West Asia and North Africa (WANA) countries can be considered among those having contributed the least to global greenhouse gas emissions, they are considered the region most susceptible to climate change impacts for many reasons: (1) all scenarios expect significant increases in temperature and reductions in precipitation, (2) the high dependence of resident communities on natural resources and livestock for their livelihoods, (3) the poverty in many parts of the region increases the vulnerability of affected people to respond to an increased incidence of drought and floods and (4) the overuse of natural resources renders them less resilient to the impact of higher temperatures and lower and more variable precipitation (Seo and Mendelsohn 2006).

In the WANA region, climatic changes could lead to a shortage of water resources, widespread land degradation and increased desertification. These threats could also have a major impact on rangeland biodiversity, the life cycle of plants, and productivity due to lack of rain and repeated periods of drought. Moreover, they may reduce the resilience of rangeland ecosystems as shown for the Stipa tenacissima ecosystem in North Africa (Ben Salem et al. 2007), where they suffer from advanced deterioration in recent years as a result of combined effects of disturbance and frequent droughts. Climate change will increase the negative impacts of drought on rangeland vegetation such as low emergence of annual species; changes in phenology and the timing of reproduction; reduced biodiversity; low plant cover; and decline of the productive capacity in pastoral systems (Ouled Belgacem et al. 2008). Several scientists (Elith et al. 2006; Phillips et al. 2006) expect that plant species will migrate to other areas, where they may better meet their ecological requirements.

A large portion of the WANA region is arid or semi-arid with shallow and low fertility soils and poor plant cover. Additionally, this region has experienced increased human populations, urbanization, and elevated food consumption above the region's production capacity; as well as costly and unsustainable production (El Kharraz et al. 2012). In this region, rangelands represent the single largest land use type, covering over two-thirds of the total land area with over 1.7 billion ha and provided most of the feed resources for livestock in the past (Steinfeld et al. 2006). However, today their contribution has been greatly reduced and in most WANA countries natural feed resources do not provide more than $20 \%$ of livestock needs (Nordblom and Shomo 1993).

In WANA region, the natural vegetation cover, mainly composed of very sparse steppe species, has been altered by various human activities (Le Floc'h 1995). Conversion of natural ecosystems to farmland, exploitation through selective harvesting, fuel wood removal, charcoal production and livestock overgrazing are the major causes of degradation, habitat change and biodiversity loss (Reyers 2004). Disturbances created by these activities 
influence ecosystem dynamics, structure and composition at the local and regional scales, and are important in structuring plant communities (Hubbell et al. 1999).

Most rangelands in the WANA region exhibit arid or semi-arid climates with low and unpredictable precipitation and wide temperature fluctuations. Consequently natural vegetation has developed various mechanisms to adapt to these seasonal changes in temperature, by reducing growth rates, photosynthetic rates, mineral absorption and tissue regeneration, and by increasing concentrations of secondary metabolites (Jochum et al. 2007). However, these mechanisms could not be able to cope with the anticipated severe climate change.

The last few decades have seen an increased interest in the use of species distribution models (Guisan and Thuiller 2005). These models are empirical, in nature, relating species data (either simple presence, or presence-absence) to environmental predictor variables. Environmental predictors can exert direct or indirect effects on species and must be optimally chosen to reflect the three main types of influences on the species: (i) limiting factors related to species eco-physiology (e.g. temperature, water, soil composition); (ii) natural or human-induced disturbances, and (iii) resources (e.g. energy and water) that can be assimilated by organisms (Guisan and Thuiller 2005). The environmental data related to these three main types of influence on species distribution are best manipulated within a geographical information system (GIS). Maximum entropy approaches have also grown dramatically over the few last years. These approaches are based on the use of presence-only data for modeling species distribution. Presence-only methods are necessary because the absence of a species is difficult to demonstrate, and because false absences can decrease the reliability of the predictive models (Phillips et al. 2006).

The vulnerability to climate change was defined as the degree to which a system is susceptible to, or unable to cope with, adverse effects of climate change, including climate variability and extremes (Carter et al. 2007). This concept which emphasizes the potential for harm is more focused on outcomes resulting from climate change. It also explicitly recognizes the social dimension of vulnerability in the form of coping capacity (Preston and Stafford-Smith 2009). Coping with, or adapting to, extreme climatic events involves both biophysical and socioeconomic factors. Therefore, a system's vulnerability depends not only on it being exposed to increasing problematic climatic events, but also on its environmental and social characteristics that will affect the impact of the anomalous weather (Máñez Costa et al. 2011). Indeed, climate is one driver of system behavior, and other drivers may also be undergoing significant change (e.g. land use and/or demographic change) (Preston and Stafford-Smith 2009).

Species vulnerability assessments consider vulnerability to climate change as the extent to which a species (within a defined geographical area) is susceptible to harm from climate impacts (Schneider et al. 2007). These assessments can be used to identify which species are likely to be significantly impacted by projected climate changes, and to assist in understanding why they may be vulnerable. A number of vulnerability assessment tools have recently been developed to assist land managers in evaluating and prioritizing actions taken in response to climate change, including mitigation strategies such as assisted migration (Fitzpatrick et al. 2008). In order to enhance the adaptation of rangeland species to ongoing climate change by increasing their resilience, an assessment of their vulnerability to this risk is needed first. This study aimed to evaluate the impact of climate change on the geographical distribution of selected native plant species from the Syrian and southern Tunisia rangelands. 


\section{Materials and methods}

\subsection{Study areas}

Two representative areas of the WANA region were selected for the study, the Syrian rangelands $\left(34^{\circ} 28^{\prime} 45^{\prime \prime} \mathrm{N}\right.$ and $\left.38^{\circ} 35^{\prime} 00^{\prime \prime} \mathrm{E}\right)$ and southern Tunisia $\left(32^{\circ} 45^{\prime} 00^{\prime \prime} \mathrm{N}\right.$ and $10^{\circ}$ $20^{\prime} 75^{\prime \prime} \mathrm{E}$ ). The Syrian rangelands cover a total area of 10 million ha, or $55 \%$ of the country's land area, and stretches over large parts of central and eastern Syria (ACSAD 2004; Louhaichi and Tastad 2010). The soils of Syrian Badia belong to the order of Aridisols (the 1975 United States Department of Agriculture Soil Taxonomy), mostly characterized by Calcic or Gypsic horizons close to the soils surface, weak structure and relatively light texture, which predisposes them to erosion (ACSAD 2004). Characterized by low rainfall ( $<200 \mathrm{~mm}$ per year), which decreases from west to east, it is suitable only as grazing land for small ruminants, equines and camels. The Bedouin communities that inhabit the rangelands herd about 12 million animals within this area, predominantly sheep, but also goats (about 1.6 million) and camels (about 27,000) (ACSAD 2004). This high stocking rate is beyond the appropriate carrying capacity, and has led to drastic deterioration of the native rangelands and depleted their contribution to successful animal production systems (Louhaichi et al. 2012). Only the middle part of the rangelands $(2,831,988 \mathrm{ha})$ is relevant to this study.

The Medenine prefecture is a representative area of southern Tunisia that covers about 626,815 ha. It is limited in the east by the Mediterranean Sea and crossed by the Matmata mountain chain as a bioclimatic barrier between the arid and the Saharan climate. Grazing is the dominant land use and consists mostly of dwarf ligneous vegetation, known locally as steppes. The climate is arid Mediterranean with low and irregular rainfall (100-200 mm) with hot and dry summers. According to the French system of soil classification, the soils of the study area are poor and marginal and classified as xerosols with raw minerals covering hard rocks, coarse colluvium or calcareous and gypsum crusts (Mtimet 2001). These steppes are mostly overgrazed due to the relatively high number of grazing animals (511,270 head) mainly composed of sheep $(301,000)$, goats $(188,000)$ and camels $(13,000)$.

\subsection{Target shrub species}

Three dwarf shrub species representing two genera from the Chenopodiaceae family were selected for assessment of their vulnerability to climate change. The species common to both study areas was Salsola vermiculata L., Mediterranean saltwort, a dominant perennial species in the Mediterranean arid zone. It grows on sandy-silt soils in the lowlands and the slightly saline alluvial plains. It is well known for its high palatability and range value for small ruminants and camels (Assaeed 2001). The second genus Haloxylon is represented by two invasive species: H. salicornicum (Moq.) Bunge in the Syrian rangelands and H. schmittianum Pomel in southern Tunisia. Both species have comparable ecological requirements and range values. They are dwarf shrubs growing in hot, dry areas on shallow to deep sands or silty soils, and also found in gravel plains. Despite their relative importance as camel browse, they are of low range value and palatability for small ruminants and constitute an indicator of fair rangeland condition (Assaeed 1996). The current distribution maps of the target species (Salsola and Haloxylon) are extracted from those achieved within the framework of the National Forest and Pastoral Survey in Tunisia (RSNC 2007) and the Syrian Badia (= rangelands) project (ACSAD 2004). 


\subsection{Environmental and socioeconomic data}

Environmental data included eight climatic layers, three soil property layers, plus an altitude layer. The current climate of both study areas was described by eight climate variables (mean annual temperature, minimum temperature of the coldest month, maximum temperature of the warmest month, temperature seasonal variation, mean annual precipitation, precipitation of wettest month, precipitation of driest month and precipitation seasonal variation) downloaded from the layers of the world climate database (www.worldclim.org). This database also provided information on the altitude surface of the distribution of the target species in the area. The data (Shape ESRI Grid, 2.5 arcmin resolution) and altitude were downloaded from the WorldClim database (Hijmans et al. 2005). The three soil variables included soil texture (i.e. percentage of clay, silt and sand contents), soil depth and soil salinity. In arid areas, these variables are considered critical to the spatial distribution of plant species (Floret and Pontanier 1982). These layers were extracted from the regional agriculture map of the governorate of Medenine in Tunisia (www.carteagricole.agrinet.tn) and from the Syrian Badia Development Project. In both countries, the scale of these layers is $1 / 50,000$.

Climatic projections, using the same eight variables as the current situation, were achieved for the years 2020 and 2050 using the average of predictions of the widely used global circulation model HADCM3, within the frame of the A2 scenario of $\mathrm{CO}_{2}$ emissions (IPCC 2000). Data (grid format, 2.5 arcmin of resolution) were downloaded from the gisweb database (www.gisweb.ciat.org).

Since environmental parameters only enable assessing the sensitivity of target species to climate change, the use of socioeconomic parameters describing the human pressure is necessary to assess the species vulnerability (O'Brien et al. 2004). In this case grazing is the main common use in both study areas. Consequently, the socioeconomic layer was represented by a synthetic variable called the Coefficient of Overgrazing (CO), which aims to estimate the current state of the species in relation to animal pressure (i.e. species are overgrazed, moderately grazed or under grazed):

$$
\mathrm{CO}(\%)=1-\mathrm{GC} / \mathrm{SD}
$$

Where GC is grazing capacity and SD is stocking density.

The map of this variable (1/50,000 scale) was generated from the current grazing capacity (determined from the rangelands units production map) and from the stocking density map as expressed by the spatial distribution of the herds in both study areas (ACSAD 2004, MAWR 2004). In order to emphasize the impact of climate change, it was assumed that grazing pressure (the main land use) is kept unchanged for both 2020 and 2050. Otherwise the modeling exercise would be complicated by the interactions of biotic and abiotic factors.

\subsection{Species spatial distribution modeling}

Climate envelope modeling is a tool to easily assess the potential impact of climate change on species spatial distributions. This type of modeling uses geographic distributions of documented species to predict the location of its climatic niche, i.e. the possible presence of the species. Future shifts in climatic niche are then estimated based on climate projections from global circulation models.

To meet the study objectives, the ecological niche concept (Phillips et al. 2006) was applied, which emphasized the relationship between species occurrence and environmental parameters. The species distribution modeling software MaxEnt (Maximum Entropy) was 
considered the most suitable model for this case, and was a recent implementation of a statistical approach which characterized probability distributions from incomplete information (Phillips et al. 2006). The latter authors enumerated many advantages of using Maxent, compared to other modeling approaches. The most important were: (1) the model requires only presence data, together with environmental information for the study area, (2) the occurrence data could represent an incomplete sample of an empirical probability distribution, (3) the unknown distribution could be most appropriately estimated as the distribution with maximum entropy as subjected to constraints imposed by environmental variables, and (4) the distribution of maximum entropy approximated the potential geographic distribution of the species. It was also indicated that Maxent was relatively insensitive to spatial errors associated with location data, requires few locations to construct useful models, and performs better than other presence-only modeling approaches (Baldwin 2009). However, in Maxent different prior assumptions were reflected in the method of background sample selection and accounting for sampling bias. Because it is an 'only presence' data model, a species may be recorded as absent instead of present at a given location if it could not be detected, or the species may be absent but the habitat is suitable, or the habitat may truly be unsuitable for the species, with the former two situations leading to the possible identification of a false absence (Ortega-Huerta and Peterson 2008). By default, when using Maxent the assumption was made that the species occurrence data were unbiased and independent samples were based on the distribution of the species (Phillips et al. 2006). As for other ecological or bioclimatic models, in Maxent the most important assumption was that the distribution of species was determined wholly or partly by climate (Aruju and Peterson 2012). The selected environmental variables (climatic and soil) were considered key factors for species distribution in Maxent (assumptions). However, other factors such as interspecific interactions can also play an important role in the distribution of the species and were not considered by the model. These interactions could be either positive (e.g., mutualists such as seed dispersors, pollinators, etc.) or negative (e.g., competitors, predators, diseases). By limiting or enhancing population processes, interactions could obviously affect distributions. Moreover, this model was only capable of predicting the relative probability of occurrence. Considering this, plus the quality of the opportunistically collected occurrence data and its coarse resolution, and the remotely sensed environmental data, predictions need to be interpreted cautiously when creating range maps and when using them to answer complex ecological questions. In many cases, Maxent was best suited for hypothesis generation and for asking better questions, but not for answering them. For this case MaxEnt (Version 3.3.3a) was utilized, as it seemed the most suitable approach for modeling species spatial distributions under both current (Elith et al. 2006; 2011) and future environments (Hijmans and Graham 2006). The model validation was conducted by comparing the maps predicting of the vulnerability of both species for the current situation with maps of the actual current distribution. Model validation was achieved by the use of a certain number of iterations or training points as it was required by the model.

\section{Results}

In addition to the areas where $S$. vermiculata has been recorded in the Syrian rangelands, it could potentially occupy several other sites where its ecological requirements may be met and the current environmental conditions, including climate, would be favorable for its distribution in the region (Fig. 1). However in south-eastern Tunisia, the potential geographical distribution of $S$. vermiculata was limited to the middle portion of the target area, 
between the coast and the mountain chain (Fig. 2). In the study areas, S. vermiculata was apparently highly vulnerable to ongoing climate change combined with human pressure, i.e. grazing (Figs. 1 and 2). This was more significant at the horizon of 2050, when the geographical distribution would be restricted to small and scattered ecological niches, where the plant may meet its requirements. The contributions of environmental and socioeconomic variables in explaining these trends are presented in Table 1. Among the environmental variables, the variation of temperature seasonality (32.2 and $28.5 \%$ in Syria and Tunisia, respectively) followed by mean annual precipitation (26.2 and $28.7 \%$, in Syria and Tunisia, respectively) were the main variables restricting the geographical distribution of $S$. vermiculata in both study areas. The precipitation of the wettest month (15-18\%) was the third most important variable limiting the distribution of $S$. vermiculata. There were no important effects of the other variables on the trends of $S$. vermiculata distribution-mainly those related to geomorphology and edaphic conditions of the site. $S$. vermiculata is well adapted to extremes of temperature and summer drought, as confirmed by the low contributions of the related variables. However, the socioeconomic variable (i.e. CO) contributed 10 and $12 \%$ in Syria and Tunisia, respectively, and seemed to enhance the former climatic parameters' impact on the species' resilience capacity. In fact $S$. vermiculata, a highly palatable range species and continuously threatened by overgrazing, is coming under greater threat.

Compared to $S$. vermiculata, the situation was completely opposite for $H$. salicornicum and H. schmittianum (Figs. 3 and 4). Having comparable ecological needs, currently both species only partially occupied the study areas. However, the model outputs showed an important invasion of study areas by Haloxylon spp. by 2020 and mainly 2050. It is apparent that the ongoing climate change will favor these species and lead to ecological conditions similar to those required for their establishment and growth. The mean annual precipitation was the main factor explaining these trends with 55-60\% contribution (Table 1). With their large suitable rainfall range (200-300 mm or less), decreased rainfall will enhance invasion of the study areas by these Haloxylon spp. Temperature seasonality (14.6-16.4\%) and minimum temperature of the coldest month (10.2-13.5\%) came in second and third classes, respectively. Together these three parameters explained 80-90\% of the expected geographical distribution of these species. Moreover, Haloxylon spp. apparently had greater tolerance for warmer and drier conditions (i.e. very low contributions of maximum temperature of the warmest month and precipitation of the wettest month, respectively). As was the case for $S$. vermiculata, the geomorphology of the area and its edaphic conditions did not constitute constraints toward the establishment and development of Haloxylon spp., thus confirming their broad ecological niches. The current abundance of Haloxylon spp. in their community testifies to their low range value and palatability mainly for small ruminants (the main livestock type in both study areas), and may explain the low contribution of $\mathrm{CO}(3.2-5.3 \%)$
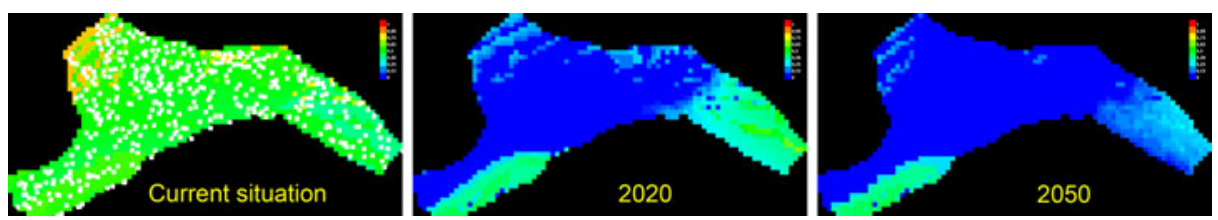

Fig. 1 Potential geographical distribution of $S$. vermiculata in the Syrian rangelands under present climate and the HADCM3 global circulation model for 2020 and 2050. Maxent produces a continuous prediction with values ranging from 0 (blue) to 1 (red). The higher the predicted value the more suitable the environmental conditions for the species. In the current situation map, white pixels represent random training sites generated by the model for calibration purposes 

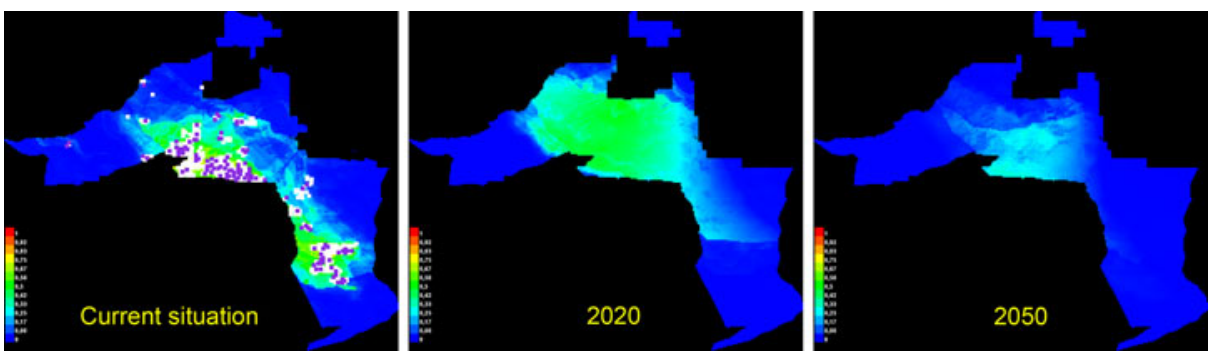

Fig. 2 Potential geographical distribution of $S$. vermiculata in southern Tunisia under present climate and the HADCM3 global circulation model for 2020 and 2050. Maxent produces a continuous prediction with values ranging from 0 (blue) to 1 (red). The higher the predicted value the more suitable the environmental conditions for the species. In the current situation map, purple pixels represent random training sites generated by the model for calibration purposes

to their predicted distribution. For all these reasons, it is unsurprising that these two plant species are expected to increase under climate change stresses.

\section{Discussion}

All climate projection scenarios indicate that the WANA region will be exposed to three key climate change hazards: (i) long-term climatic desiccation; (ii) increased weather/climate variability, extremes and uncertainty; and (iii) rising temperature. Vulnerability to each of these hazards varies among countries, depending on the socioeconomic situation and level of technology development (Bazza 2009). Thus many valuable ecosystems could be lost as rangeland species fail to keep up with the shift in climate boundaries. This is related to the

Table 1 Contribution (\%) of environmental and socioeconomic variables in explaining the current and predicted geographical distribution of $S$. vermiculata in two areas of the WANA region

\begin{tabular}{|c|c|c|c|c|}
\hline \multirow[t]{2}{*}{ Variables } & \multicolumn{2}{|c|}{ Syrian rangelands } & \multicolumn{2}{|c|}{ Southern Tunisia } \\
\hline & S. vermiculata & H. salicornicum & S. vermiculata & H. schmittianum \\
\hline Precipitation of wettest month & 18.8 & 0 & 15.3 & 0.1 \\
\hline Minimum temperature of coldest month & 1.2 & 10.2 & 0.1 & 13.5 \\
\hline Precipitation seasonality & 0.8 & 0.8 & 1.7 & 2.2 \\
\hline Temperature seasonality & 32.2 & 14.6 & 28.5 & 16.4 \\
\hline Annual precipitation & 26.2 & 59.2 & 28.7 & 54.5 \\
\hline Annual mean temperature & 4.1 & 0 & 5.4 & 0.5 \\
\hline Precipitation of driest month & 0 & 0 & 0.1 & 0.6 \\
\hline $\begin{array}{l}\text { Maximum temperature of warmest } \\
\text { month }\end{array}$ & 0 & 3.3 & 1.5 & 2.5 \\
\hline Altitude & 6.2 & 4.2 & 5.4 & 3.3 \\
\hline Soil depth & 0.3 & 1.2 & 0.7 & 0.6 \\
\hline Soil texture & 0 & 0 & 0 & 0 \\
\hline Soil salinity & 0 & 1.2 & 0.5 & 2.6 \\
\hline Coefficient of Overgrazing (CO) & 10.2 & 5.3 & 12.1 & 3.2 \\
\hline
\end{tabular}



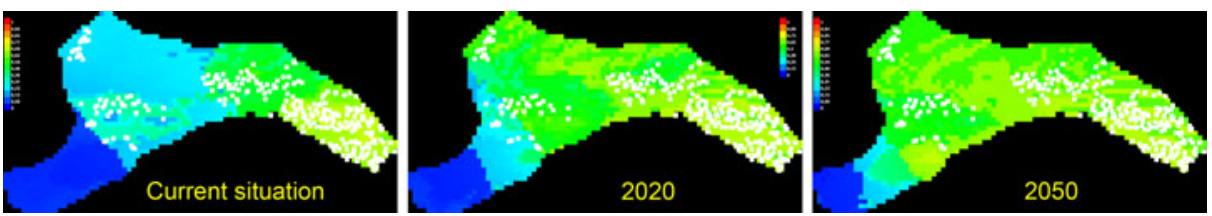

Fig. 3 Potential geographical distribution of $H$. salicornicum in the Syrian rangelands under present climate and the HADCM3 global circulation model for 2020 and 2050. Maxent produces a continuous prediction with values ranging from 0 (blue) to 1 ( red). The higher the predicted value the more suitable the environmental conditions for the species. In the current situation map, white pixels represent random training sites generated by the model for calibration purposes

ability of a species to migrate, its ability to adapt to its current place, and its plasticity, vulnerability and associated sub-factors. For example, the ability to move would involve seed dispersal, seed size, dispersal distance and age of reproduction, as well as habitat specificity and availability. The latter two parameters would be influenced by fragmentation and isolation. The ability to adapt in place would be a function of genetic variation, population size, fecundity and gene flow between populations. Plasticity is an assessment of the species' resilience and environmental buffering capacity (Johnston et al. 2010).

The vulnerability of $S$. vermiculata to climate change seemed to be explained by its sensitivity to the lack of moisture and the seasonal variation in temperature. The germination of $S$. vermiculata was not likely to occur under low soil moisture levels, as low soil moisture availability would not ensure seedling establishment (Osman and Ghassali 1997). This was also consistent with findings for several desert plant species (Assaeed 2001). This species commonly occured in nature in wadi beds, where adequate moisture may be available (Assaeed 2001). The predicted increase of temperature in the WANA region, mainly beyond the year 2050, may partially explain the species projected sensitivity. S. vermiculata produces short-lived seeds during winter and consequently seasonal variation and increased temperature may limit plant germination and survival (Assaeed 2001). Moreover, the increase in temperature may negatively affect the longevity of $S$. vermiculata seeds, which need a low storage temperature (Osman and Ghassali 1997). The high sensitivity to climate change of $S$. vermiculata may also be explained by its low genetic diversity and short seeddispersal distance. However, the high vulnerability of $S$. vermiculata, cannot be explained by its sensitivity to the predicted changes alone. Apparently, high grazing pressure may disturb the adaptive capacity of $S$. vermiculata to drought and climate change.
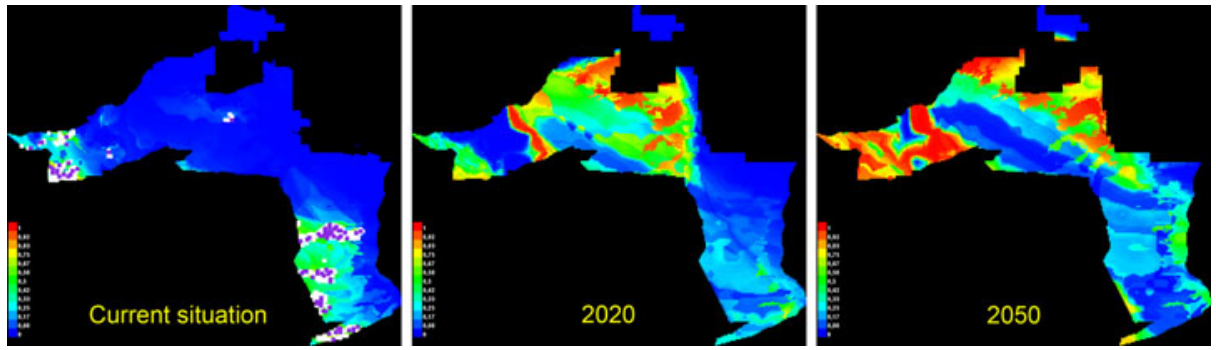

Fig. 4 Potential geographical distribution of $H$. schmittianum in Southern Tunisia under present climate and the HADCM3 global circulation model for 2020 and 2050. Maxent produces a continuous prediction with values ranging from 0 (blue) to 1 (red). The higher the predicted value the more suitable the environmental conditions for the species. In the current situation map, purple pixels represent random training sites generated by the model for calibration purposes 
It has been shown that drought and grazing are convergent selective forces and that the combined effect of drought and overgrazing is particularly detrimental to the re-growth of palatable perennial species, as was the case for S. vermiculata (Quiroga et al. 2010). Overgrazing of these high value rangeland species seems to be the main threat to the resilience of these groups, even when classified as having a low sensitivity to a changing environment. Consequently, increasing the resilience capacity of this rangeland species was not only a matter of developing management strategies based on the control of grazing pressure but also looking for other measures such as rainwater harvesting techniques which may be indispensable for supplying water to plants in low rainfall conditions. Through changing climate, rainfall has become more erratic, with higher rainfall intensity, and with higher spatial and temporal rainfall variability. Furthermore, with accelerated overgrazing the bare soil becomes impervious to infiltration and the amount of run-off increases. The result will be increased risk for annual droughts and intra-seasonal dry spells. Rainwater catchment technologies, such as pits and contour lines, will be necessary to enhance pastures and promote plant growth (Pandey et al. 2003).

Climate change seems to favor Haloxylon spp., since the modeling results predicted invasion by these species of new areas by 2020 and 2050. In fact, these xerophilous species are well known for their adaptation to drought and higher temperatures, in addition to their tolerance to a wide range of soil properties (Salama et al. 2005). The low sensitivity of the Haloxylon spp. to the major environmental variables tested may due to the xeromorphic characteristics they have developed as a result of adaptation to drought, salinity, poor nutrition, strong wind, sand movement and high light intensity (Huang et al. 2003). This adaptation is expressed in their reduced leaf size and photosynthesis function of the succulent branches. In addition, the formation of anomalous structures in the root and stem can be considered ecological adaptations to extreme drought and temperatures. Not only resistant to drought and high temperatures, Haloxylon spp. also tolerates salinity, and they are known as xero-halophytes (Huang et al. 2003). They also constitute an indicator of desertification, since sites invaded by Haloxylon spp. are generally characterized by an accumulation of moving sand. Whatever the soil conditions, H. schmittianum reportedly reacts rapidly to early rainfall even in small quantities. Shedding seeds during NovemberDecember, it responds quickly to moisture in terms of germination and seedling establishment (Assaeed 1996). This confirms the wide distribution of these species in the arid and desert areas of WANA with average annual rainfall of 200-300 mm or less. Moreover, the low susceptibility or even invulnerability of Haloxylon spp. to projected climate changes both in Syria and Tunisia is mainly due to the low grazing pressure exerted on these species due to their very low palatability and range value (Assaeed 1996).

In addition to climate, soil conditions and human disturbance, plant competition and other factors also influence the presence of species, and probably constitute additional barriers to their distribution (Guma et al. 2010). However, since the climate is considered primarily responsible for future changes in distribution, most modeling predictions ignored these other factors (Guisan and Theurillat 2000). Nevertheless, the results of the present modeling contain a certain amount of uncertainty. Despite its limitations, ecological niche modeling may be considered a useful tool for obtaining a first approximation of the potential impact of climate change on species presence (Pearson and Dawson 2003). Modeling outputs may provide more accurate results if already available new technologies based on geospatial information and satellite data are used. These technologies permit to determine the risk and vulnerability of a system to a drought and to develop monitoring and drought prediction systems based on real-time information to support decision making. In fact, with the advances in sensor instruments and analytical methods, mapping and monitoring the spatial 
distribution of rangeland vegetation in arid and semi-arid environments has improved tremendously. Detailed spectral resolution (multispectral and hyperspectral) for discriminating vegetation at species level are becoming more readily available at lower cost (Mansour et al. 2012).

\section{Conclusions}

The combined effects of climate change and animal pressure on rangelands of the WANA region may have significant adverse impacts on range species under high $\mathrm{CO}_{2}$ emissions scenarios. Rangeland species already threatened, such as $S$. vermiculata, are likely to come under greater danger and present a very high vulnerability to climate change. On the other hand species with low range value and broad ecological niches (i.e. H. salicornicum and $H$. schmittianum) were favored by the impacts of climate change and seemed to be able to survive under future environmental conditions of their adaptation range.

Although these results need cautious interpretation in light of the many assumptions underlying the model and the data used, the impacts identified warrant a clear focus on monitoring across species ranges to detect early signs of change. Experiments are needed that determine physiological thresholds for species in order to validate and refine the model. Clearly, an adaptation strategy to increase the resilience of the most vulnerable species based on better control of grazing pressure, the selection of more drought tolerant taxa and the establishment of other mitigation measures, such as water harvesting techniques, need to be developed for the WANA region.

Although, considerable progress has been made with respect to mapping and monitoring rangeland vegetation using remote sensing data, more research is needed using large scale (higher resolution) geospatial information to enhance our ability to discriminate between vegetation species and reach more accurate output.

Acknowledgments This work was supported by the International Center for Agricultural research in the Dry Areas (ICARDA) and the CGIAR Research Program on Climate Change, Agriculture and Food Security (CCAFS). The authors thank Dr Maarten van Gingel and Dr Rolf Sommer for their critical review.

Open Access This article is distributed under the terms of the Creative Commons Attribution License which permits any use, distribution, and reproduction in any medium, provided the original author(s) and the source are credited.

\section{References}

ACSAD (2004) A Survey of the Natural Resources of the Syrian Steppe. Damascus, Syria

Aruju MB, Peterson AT (2012) Uses and misuses of bioclimatic envelope modeling. Ecology 93(7):1527-1539 Assaeed AM (1996) Hammada elegans-Rhazya stricta competitive relationships in a deteriorated range site in Raudhat Al-khafs, Saudi Arabia. J Agric Sci Mansoura Univ 21:957-964

Assaeed AM (2001) Effect of temperature and water potential on germination of Salsola villosa Del. ex Roem. et Schult. Assiut J Agric Sci 32:173-183

Baldwin RA (2009) Use of maximum entropy modeling in wildlife research. Entropy 11:854-866

Bazza M (2009) Climate change in the NENA Region: Challenges and opportunities for reducing vulnerability of agriculture and food security. NENA Climate Change Forum, Rome (Italy), 8-9 November 2009

Ben Salem F, Tarhouni M, Ouled Belgacem A, Neffati M (2007) Impact of drought on plant cover dynamics in two natural areas of southern Tunisia. J Biol Sci 7(8):1539-1544

Carter TR, Jones RN, Lu X et al (2007) New assessment methods and the characterisation of future conditions. In: Parry ML, Canziani OF, Palutikof JP, van der Linden PJ, Hanson CE (eds) Climate change 2007: Impacts, adaptation and vulnerability. Contribution of Working Group II to the Fourth Assessment 
Report of the Intergovernmental Panel on Climate Change. Cambridge University Press, Cambridge, pp $133-171$

El Kharraz J, El-Sadek A, Ghaffour N, Mino E (2012) Water scarcity and drought in WANA countries. Procedia Eng 33:14-29

Elith J, Graham CH, Anderson RP et al (2006) Novel methods improve prediction of species' distributions from occurrence data. Ecography 29:129-151

Elith J, Steven J, Phillips SJ et al (2011) A statistical explanation of MaxEnt for ecologists. Divers Distrib $17: 43-57$

Fitzpatrick MC, Gove AD, Sanders NJ, Dunn RR (2008) Climate change, plant migration, and range collapse in a global biodiversity hotspot: the Banksia (Proteaceae) of Western Australia. Glob Chang Biol 14:1337-1352

Floret C, Pontanier R (1982) L'aridité en Tunisie présaharienne : climat, sol, végétation et aménagement. Travaux et document de l'ORSTOM n ${ }^{\circ} 150$. Paris, Orstom editions

Guisan A, Theurillat JP (2000) Assessing alpine plant vulnerability to climate change: a modeling perspective. Integr Assess 1:307-320

Guisan A, Thuiller W (2005) Predicting species distribution: offering more than simple habitat models. Ecol Lett 8:993-1009

Guma IR, Padrón-Mederos MA, Santos-Guerra A, Reyes-Betancort JA (2010) Effect of temperature and salinity on germination of Salsola vermiculata L. (Chenopodiaceae) from Canary Islands. J Arid Environ 74(6):708-711

Hijmans RJ, Graham CH (2006) The ability of climate envelope models to predict the effect of climate change on species distributions. Glob Chang Biol 12:2272-2281

Hijmans RJ, Cameron SE, Parra JL et al (2005) Very high resolution interpolated climate surfaces for global land areas. Int J Climatol 25:1965-1978

Huang Z, Zhang X, Zheng G, Gutterman Y (2003) Influence of light, temperature, salinity and storage on seed germination of Haloxylon ammodendron. J Arid Environ 55:453-464

Hubbell SP, Foster RB, O’Brien ST et al (1999) Light-cap disturbances, recruitment limitation, and tree diversity in a neotropical forest. Science 283:554-557

IPCC (2000) Summary for Policymakers. Emissions Scenarios. A Special Report of IPCC Working Group III. WMO-UNEP

IPCC (2007) In: Solomon S, Qin D, Manning M, Chen Z, Marquis M, Averyt KB, Tignor M, Miller HL (eds) Climate change 2007: The physical science basis. Contribution of Working Group I to the Fourth Assessment Report of the Intergovernmental Panel on Climate Change. Cambridge University Press, Cambridge, United Kingdom and New York, NY, USA, p 996

Jochum GM, Mudge KW, Thomas RB (2007) Elevated temperatures increase leaf senescence and root secondary metabolite concentrations in the understory herb Panax quinquefolius (Araliaceae). Am J Bot 94:819-826

Johnston LG, Whitehead S, Simic M, Kendall C (2010) Formative research to optimise Respondent Driven Sampling surveys among hard to reach populations in HIV behavioral and biological surveillance: Lessons learned from four case studies. AIDS Care 22(6):784-792

Le Floc'h E (1995) Les écosystèmes des zones arides du Nord de l'Afrique: orientation pour l'établissement d'un réseau de réserves de biosphère. In: Nabli MA (ed) Ouvrage collectif sur le milieu physique et la végétation. Essai de synthèse sur la végétation et la phytoécologie tunisienne- 5 et 6 . Faculté des sciences de Tunis/Agence de coopération culturelle et technique/MAB, Tunis, pp 309-321

Louhaichi M, Tastad A (2010) The Syrian steppe: past trends, current status and future priorities. Rangelands 32(2):2-7

Louhaichi M, Ghassali F, Salkini AK, Petersen SL (2012) Effect of livestock grazing on rangeland plant communities within Syrian landscape depressions. J Arid Environ 79:101-106

Máñez Costa MA, Moors EJ, Fraser E (2011) Socioeconomics, policy, or climate change: what is driving vulnerability in southern Portugal? Ecol Soc 16(1):28, http://www.ecologyandsociety.org/vol16/iss1/ art28/ Accessed 27 December 2012

Mansour K, Mutango O, Everson T (2012) Remote sensing based indicators of vegetation species for assessing rangeland degradation: opportunities and challenges. Afr J Agric Res 7(22):3261-3270

MAWR (Ministry of Agriculture and Water Resources) (2004) Cartes Agricoles Régionales de la Tunisie. $\mathrm{http}: / /$ www.carteagricole.agrinet.tn/GIS/TUNISIE/viewer.htm Accessed 28 January 2010

Mtimet A (2001) Soils of Tunisia. Options Méditerr 34:243-268

Nordblom TL, Shomo F (1993) Livestock and feed trends in West Asia and North Africa: past, present and future. Cah Opti Médit 1(5):15-32

O’Brien K, Leichenko R, Kelkar U et al (2004) Mapping vulnerability to multiple stressors: climate change and globalization in India. Glob Environ Chang 14:303-313 
Ortega-Huerta MA, Peterson AT (2008) Modeling ecological niches and predicting geographic distributions: a test of six presence-only methods. Rev Mex Biodivers 79:205-216

Osman AE, Ghassali F (1997) Effects of storage conditions and presence of fruiting bracts on the germination of Atriplex halimus and Salsola vermiculata. Exp Agr 33:149-155

Ouled Belgacem A, Ben Salem H, Bouaicha A, El Mourid M (2008) Communal rangeland rest in arid area, a tool for facing animal feed costs and drought mitigation: the case of Chenini Community, Southern Tunisia. J Biol Sci 8(4):822-825

Pandey DN, Gupta AK, Anderson DM (2003) Rainwater harvesting as an adaptation to climate change. Curr Sci 85(1):46-59

Pearson RG, Dawson TE (2003) Predicting the impacts of climate change on the distribution of species: are bioclimate envelope models useful? Glob Ecol Biogeogr 12:361-371

Phillips SJ, Anderson RP, Schapire RE (2006) Maximum entropy modeling of species geographic distributions. Ecol Model 190:231-259

Preston BL, Stafford-Smith M (2009) Framing vulnerability and adaptive capacity assessment: Discussion paper. CSIRO Climate Adaptation Flagship Working paper No. 2. http://www.csiro.au/files/files/ppgt.pdf Accessed 27 December 2012

Quiroga RE, Golluscio RA, Blanco LJ, Fernández RJ (2010) Aridity and grazing as convergent selective forces: an experiment with an Arid Chaco bunchgrass. Ecol Appl 20:1876-1889

Reyers B (2004) Incorporating anthropogenic threats into evaluations of regional biodiversity and prioritisation of conservation areas in the Limpopo Province, South Africa. Biol Conserv 118:521-531

RSNC (2007) Forest and Rangeland National Inventory. International Symposium on forest and rangeland inventory by remote sensing. Tunis, 11-12 June 2007

Salama FM, Abd El-Ghani MM, El Naggar SM, Baayo KA (2005) Vegetation structure and environmental gradients in the Sallum area, Egypt. Ecol Mediterr 31(1):15-32

Schneider R, Boutin S, Stelfox J, Wasel S (2007) Scenarios are plausible stories about the future, not forecasts. Ecol Soc 12(1):r4, http://www.ecologyandsociety.org/vol12/iss1/resp4/ Accessed 27 December 2012

Seo SN, Mendelsohn R (2006) Climate change adaptation in Africa: a microeconomic analysis of livestock choice. Centre for Environmental Economics and Policy in Africa (CEEPA) Discussion Paper No. 19. University of Pretoria, Pretoria, p 37

Steinfeld H, Wassenaar T, Jutzi S (2006) Livestock production systems in developing countries: status, drivers, trends. Rev Sci Tech 25(2):505-516 